Jurnal Inkofar * Volume 1 No. 2, Desember 2020 * ISSN: 2615-3645 (Print) / 2581-2920 (Online)

Tersedia secara online di: http://www.politeknikmeta.ac.id/meta/ojs/

\title{
ANALISIS PERBEDAAN SUHU DAN KELEMBABAN RUANGAN PADA KAMAR BERDINDING KERAMIK
}

\author{
Kartika Rahayu Tri Prasetyo Sari ${ }^{1}$, Elsanda Merita Indrawati ${ }^{2}$, Ary Permatadeny Nevita ${ }^{3}$ \\ 1,3Prodi Teknik Industri / Fakultas Teknik / Universitas Nusantara PGRI Kediri / \\ kartikaprasetya0207@gmail.com \\ ${ }^{2}$ Prodi Teknik Elektro / Fakultas Teknik / Universitas Nusantara PGRI Kediri / \\ elsanda07@gmail.com
}

\begin{abstract}
In a room, especially a boarding room which incidentally is not too large, comfort is one of the factors that is very influential. Therefore a comfortable boarding room can be said to be a necessity and even an absolute obligation that must exist. Among the many factors that influence the comfort of a boarding room, one that is considered quite important is the thermal factor. In this study conducted experiments related to thermal conditions in boarding rooms associated with the intermediary media. This study aims to find out how much influence is there or whether there is ceramic in the boarding room installed on the wall of the room and to find out how big the effect is on the thermal conditions in the room. In experiments related to temperature, it appears that there is a significant difference that ceramic walled rooms have lower temperatures. But the results of the humidity experiment cannot be drawn specifically because there are conditions in rooms with lower temperatures sometimes have lower humidity and sometimes higher, after an interview related to thermal comfort, it can be concluded that rooms with ceramic walls are felt to be more comfortable or cooler.
\end{abstract}

Keywords : temperature, humidity, room, ceramics

\section{ABSTRAK}

Di dalam sebuah ruangan, khususnya kamar kos yang notabene tidak berukuran terlalu besar kenyamanan adalah salah satu faktor yang sangat berpengaruh. Oleh karena itu kamar kost yang nyaman bisa dibilang menjadi sebuah kebutuhan bahkan sebuah kewajiban mutlak yang harus ada. Di antara banyak faktor yang berpengaruh terhadap kenyamanan kamar kost, salah satu yang dirasa cukup penting adalah faktor thermal. Pada penelitian ini dilakukan eksperimen terkait kondisi thermal dalam kamar kost yang terkait dengan media perantaranya. Penelitian ini mempunyai tujuan untuk mengetahui seberapa besar pengaruh ada atau tidaknya keramik pada kamar kost yang dipasang pada dinding kamar dan untuk mengetahui seberapa besarkah pegaruhnya terhadap kondisi thermal di dalam ruangan. Dalam eksperimen terkait suhu nampak adanya perbedaan yang cukup signifikan bahwa kamar berdinding keramik mempunyai suhu yang lebih rendah. Tetapi hasil dari eksperimen kelembaban tidak bisa diambil kesimpulan khusus karena ada kondisi di kamar dengan suhu lebih rendah kadang memiliki kelembaban yang lebih rendah dan terkadang lebih tinggi, setelah dilakukan wawancara terkait thermal comfort diperoleh kesimpulan kamar dengan dinding keramik dirasa lebih nyaman atau sejuk.

Kata Kunci : suhu, kelembaban, kamar, keramik

\section{PENDAHULUAN}

Kelembaban udara adalah kondisi yang menyatakan banyaknya uap air dalam udara. Ketika udara mengandung banyak air, kelembaban dapat dikatakan tinggi. Tingginya jumlah air di udara terjadi karena uap air. Jumlah uap air yang ditampung di udara tersebut sangat dipengaruhi oleh temperatur. Ketika temperatur udara rendah, uap air yang dibutuhkan untuk menjenuhkan udara sedikit. Kondisi tersebut terjadi ketika udara mulai jenuh. Pergerakan angin 
Jurnal Inkofar * Volume 1 No. 2, Desember 2020 * ISSN: 2615-3645 (Print) / 2581-2920 (Online)

Tersedia secara online di: http://www.politeknikmeta.ac.id/meta/ojs/

mempengaruhi temperatur ruangan dikarenakan adanya perbedaan tekanan. Udara yang dingin yang menyusut ketika malam hari dan memuai pada siang hari sehingga udara yang lebih ringan akan naik dan tergantikan dengan udara yang lebih dingin. Menurut Sankertadi (2013) dan Soegijono (1999) terdapat enam faktor yang mempengaruhi kelembaban udara di suatu tempat yaitu, suhu, kualitas dan kuantitas penyinaran, pergerakan angin, tekanan udara, vegetasi, dan ketersediaan air tanah di daerah tersebut.

Di dalam sebuah ruangan, khususnya kamar kost yang notabene tidak berukuran terlalu besar kenyamanan adalah salah satu faktor yang sangat berpengaruh. Terlebih kamar kost merupakan tempat penghuninya melepas lelah setelah seharian beraktivitas, atau tempat dimana para penghuninya harus fokus dan serius belajar dan mengerjakan tugas. Oleh karena itu kamar kost yang nyaman bisa dibilang menjadi sebuah kebutuhan bahkan sebuah kewajiban mutlak yang harus ada.

Kenyamanan terdiri dari kenyamanan psikis dan kenyamanan fisik. Kenyamanan psikis terkait dengan kenyamanan kejiwaan yang terukur secara subyektif. Sedang kenyamanan fisik dapat terukur secara objektif (kuantitatif) yang meliputi kenyamanan spasial, visual, audial dan termal. Kenyamanan termal merupakan salah satu unsur kenyamanan yang sangat penting karena menyangkut kondisi ruangan yang nyaman.

Variabel iklim yang berkaitan dengan kondisi kenyamanan termal menurut Baharuddin (2013) dalam Nasrullah dkk (2015) meliputi, temperatur udara, kelembaban, dan kecepatan aliran udara. Berdasar ISO 7730 (1994) dan ASHRAE (2004) terdapat beberapa standar yang berkaitan dengan kenyamanan thermal diantaranya adalah standar standar kenyamanan thermal Indonesia SNI T 14199303, yang membagi zona dalam tiga bagian yaitu, sejuk nyaman 20.5$22.8^{\circ} \mathrm{C}$, nyaman optimal $22.8-25.8^{\circ} \mathrm{C}$, hampir nyaman $25.8-27.1^{\circ} \mathrm{C}$ dengan kelembababn relatif udara $50-80 \%$. Di antara banyak faktor yang berpengaruh terhadap kenyamanan kamar kost, salah satu yang dirasa cukup penting adalah faktor thermal. Tentu akan sangat tidak nyaman untuk beristirahat atau beraktivitas jika kondisi dalam kamar kost dirasa terlalu dingin atau terlalu panas. Pada penelitian ini dilakukan eksperimen terkait kondisi thermal dalam kamar kost yang terkait dengan media perantaranya.

Salah satu proses perpindahan thermal adalah dengan proses konduksi yaitu perpindahan melalui media solid atau padat. Pada penelitian ini mempunyai tujuan untuk mengetahui seberapa besar pengaruh ada atau tidaknya keramik pada kamar kost yang dipasang pada dinding kamar. Keramik memang bukan isolator yang terbaik, dan juga bukan konduktor terbaik, maka dari itu penelitian ini digunakan untuk mengetahui seberapa besarkah pegaruhnya terhadap kondisi thermal di dalam ruangan.

\section{METODE PENELITIAN}

\subsection{Hipotesis}

Adanya keramik di dinding berpengaruh terhadap kondisi thermal di dalam kamar kost. Adanya keramik membuat suhu di dalam kamar tidak setinggi dibandingkan dengan kamar yang dindingnya tidak dipasang keramik. Selain itu secara psikologis, adanya keramik juga memberikan kesan lebih sejuk.

\subsection{Tahapan Eksperimen dan Batasan}

Tahapan eksperimen pengukuran suhu dan kelembaban pada kamar berdinding keramik dijelaskan dalam gambar diagram alir Gambar 1.

a. Eksperimen dilakukan pada dua kamar kost dengan kondisi yang berbeda, satu ada keramik di dinding dan kamar yang lain tidak ada.

b. Kedua kamar yang diamati diusahakan dalam kondisi yang sama, misal ketika satu kamar kondisi lampu mati maka kamar yang lain juga demikian.

c. Kondisi di dalam kamar diukur menggunakan termometer ruangan (pengukur sugu ruangan) dan hygrometer (pengukur kelembaban ruangan). 
d. Eksperimen dilakukan saat pagi hari, siang hari dan malam hari.

e. Kondisi kamar yang lain diabaikan.

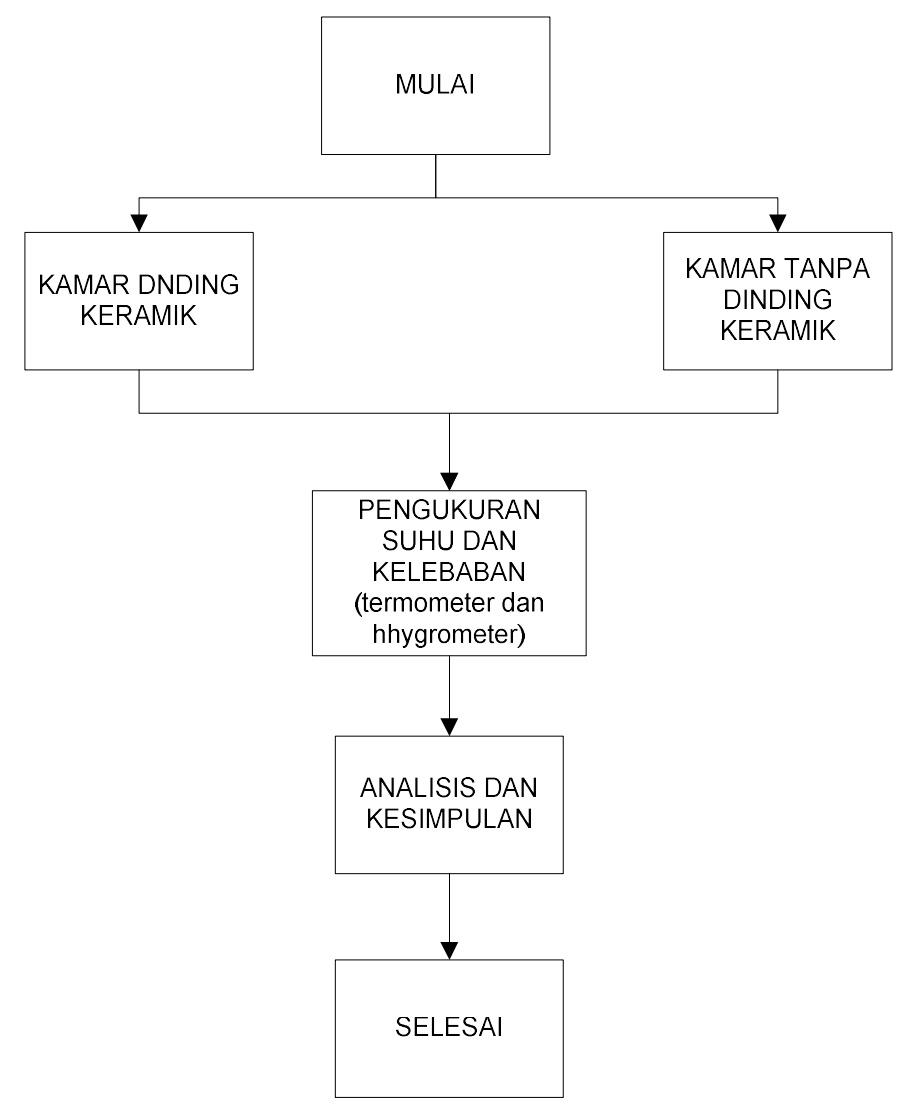

Gambar 1. Diagram alir eksperimen

\section{HASIL DAN PEMBAHASAN}

\subsection{Pengamatan Pagi Hari}

Pengamatan dilakukan pada kamar berdinding keramik dan tidak berdinding keramik yang pada pukul 06.00-08.00 dengan hari yang berbeda. Kondisi kamar yang diamati pada keadaan jendela, pintu terbuka, dan lampu menyala. Hasil yang diperoleh dari pengukuran suhu ruangan dan kelembaban dapat dilihat pada Gambar 2. 


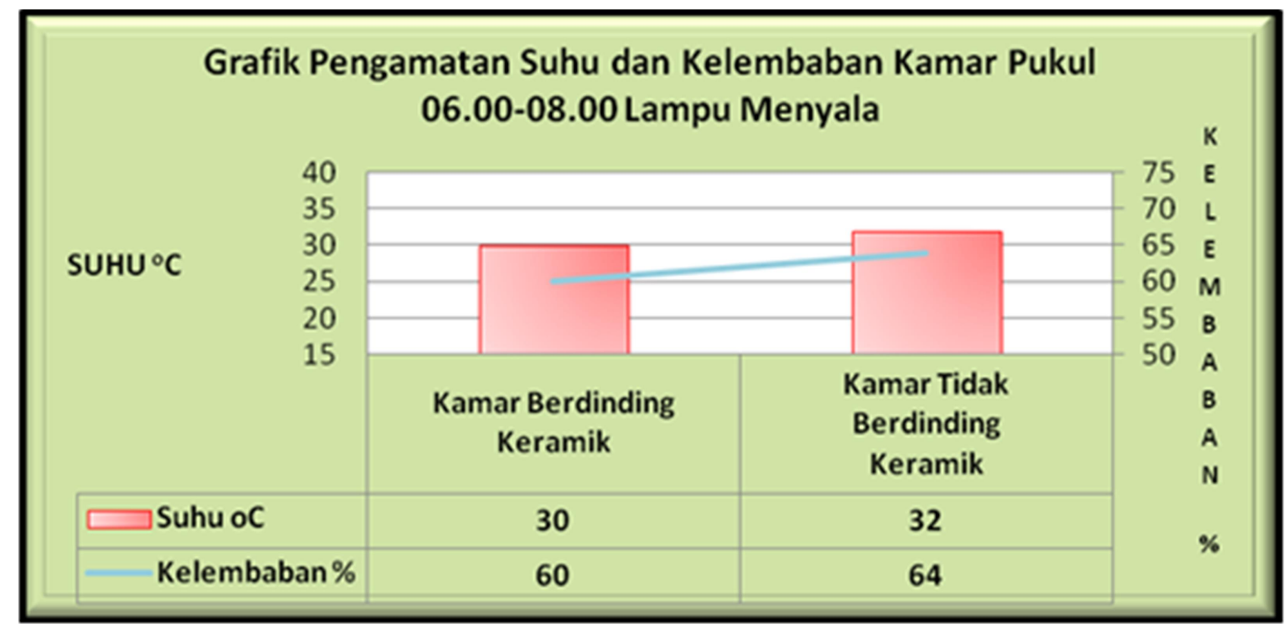

Gambar 2. Grafik pengamatan suhu dan kelembaban kamar pada pagi kondisi lampu menyala

Dari grafik pada Gambar 2 dapat dilihat bahwa suhu pada kamar berdinding keramik lebih rendah dibandingkan kamar yang tidak berdinding keramik. Kelembaban pada kamar yang berdinding keramik lebih rendah dibandingkan kelembaban pada kamar tak berdinding keramik, sehingga udaranya cukup kering dan suhu ruangan sejuk.Kelembaban rendah ini dapat disebakan kondisi lampu yang menyala menimbulkan panas, sehingga kadar air di udara juga ikut berkurang. Orang yang berada di dalam kamar yang berdinding keramik tidak merasa kepanasan dibanding orang yang berada di dalam kamar tak berdinding keramik.

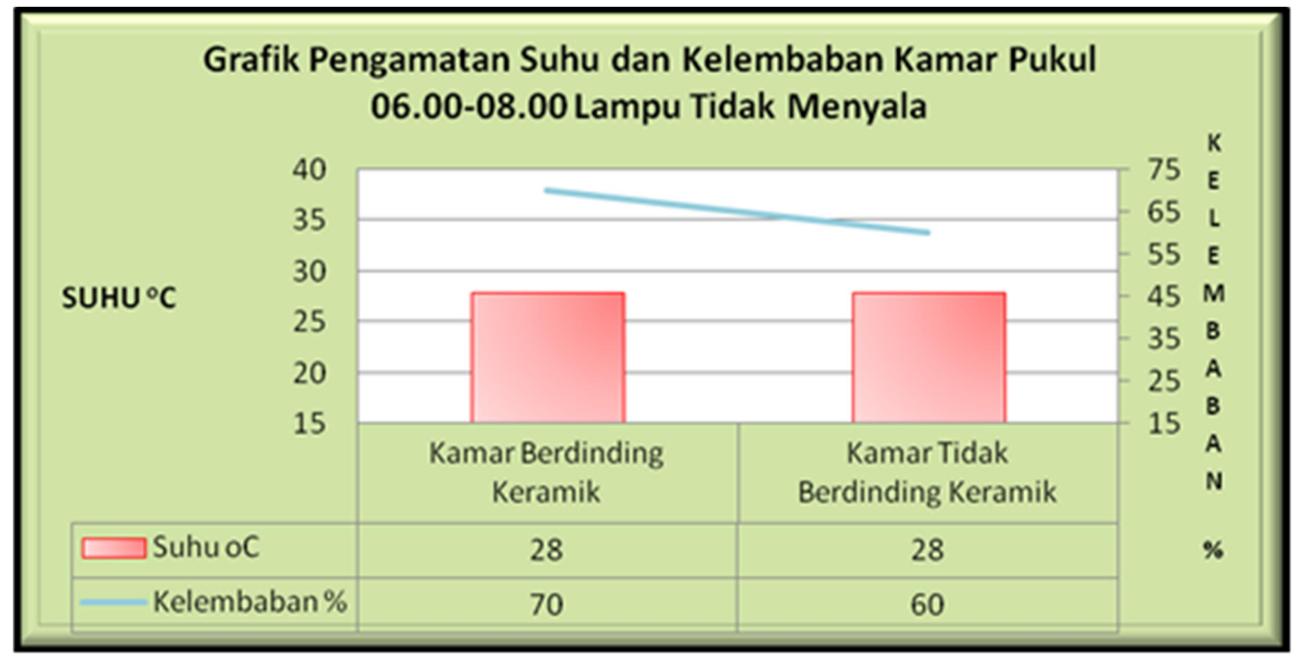

Gambar 3. Grafik pengamatan suhu dan kelembaban kamar pada pagi kondisi lampu mati

Dibandingkan dengan pengamatan yang dilakukan pada pagi hari dengan kondisi lampu tidak menyala. Pada grafik yang terdapat di Gambar 3 terlihat suhu kamar berdinding keramik dan tidak berdinding keramik memiliki hasil pengukuran suhu yang sama, yaitu $28^{\circ} \mathrm{C}$ lebih rendah dibandingkan suhu pada ruangan dengan kondisi lampu menyala. Pada tingkat kelembaban, kamar yang berdinding keramik memiliki tingkat kelembaban yang lebih tinggi dibandingkan kamar yang tidak berdinding keramik, hal ini dikarenakan udara dingin 
dikeluarkan oleh keramik. Kelembaban pada kamar yang berdinding keramik mencapai 70\%, hal ini dapat diakibatkan karena kamar yang berdinding keramik lokasinya berhimpitan dengan kamar mandi, dan aktivitas yang di kamar mandi biasanya mulai ramai pada jam tersebut.

\subsection{Pengamatan Siang Hari}

Pada pengamatan kedua dilakukan pada pukul 12.00-15.00 dengan kondisi jendela dan pintu terbuka, lampu mati.Hasil yang pengamatan terdapat pada Gambar 4.

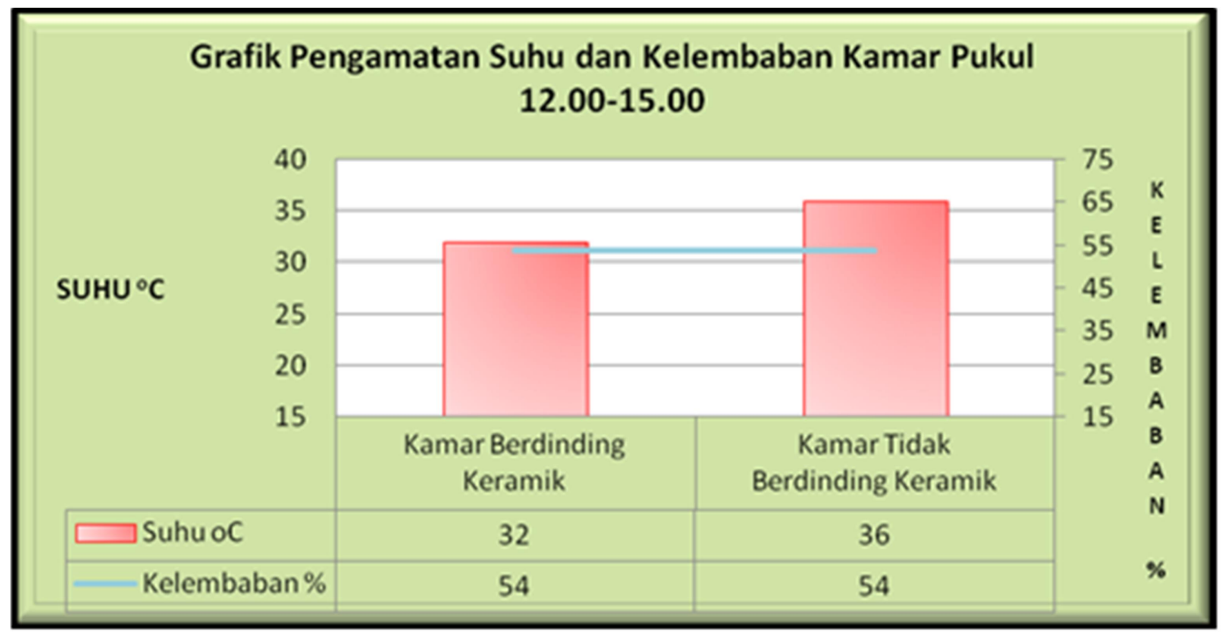

Gambar 4. Grafik pengamatan suhu dan kelembaban kamar pada siang hari

Suhu pada kamar berdinding keramik lebih rendah dibandingkan kamar yang tidak berdinding keramik. Sedangkan kelembabanya sama yaitu 54\%. Kelembaban pada kamar yang berdinding keramik tidak begitu tinggi dikarenakan hawa panas matahari yang masuk ke dalam kamar cukup tinggi.

\subsection{Pengamatan Malam Hari}

Pengamatan malam hari dilakukan malam hari pukul 19.00-21.00 dengan kondisi jendela,pintu tertutup dan lampu menyala. Berdasarkan grafik pada Gambar 5 dapat dilihat bahwa suhu pada kamar berdinding keramik lebih rendah dibandingkan suhu kamar yang tidak berdinding keramik. Tingkat kelembaban yang dihasilkan juga lebih tinggi pada kamar yang berdinding keramik. 


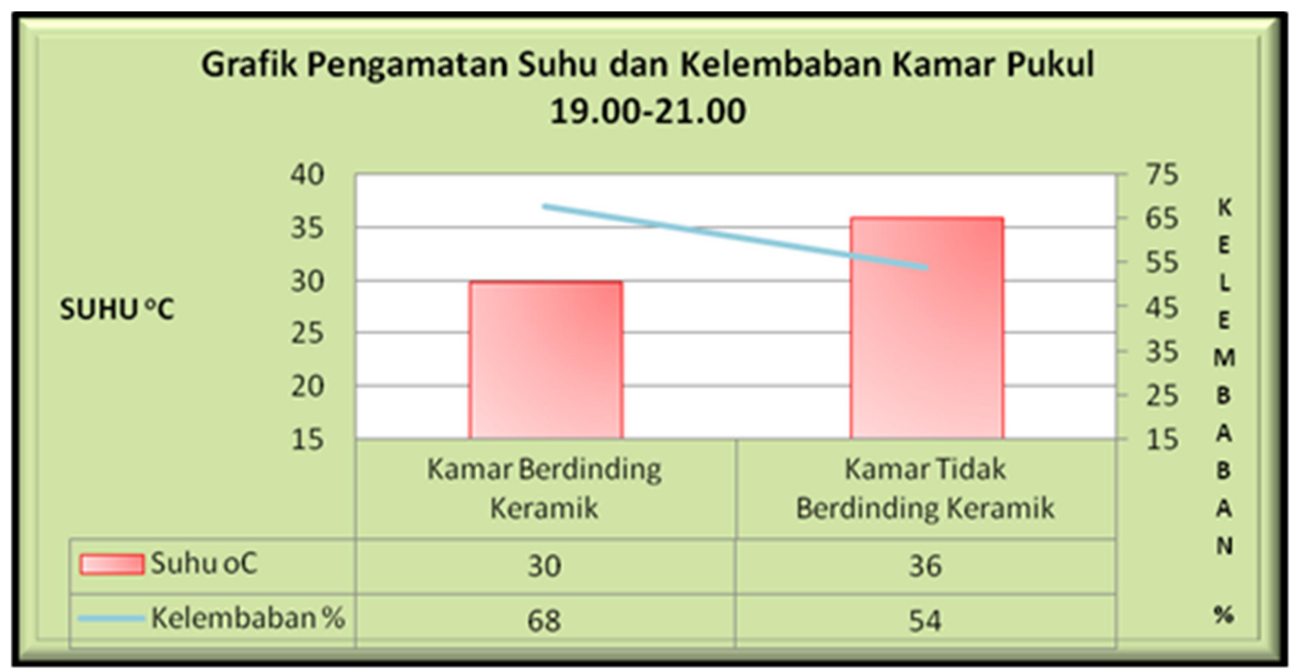

Gambar 5. Grafik pengamatan suhu dan kelembaban kamar pada malam hari

Dari tiga eksperimen yang dilakukan dengan tiga kondisi yang berbeda nampak adanya perbedaan dalam suhu dan kelembaban. Dalam eksperimen terkait suhu nampak adanya perbedaan yang cukup signifikan bahwa kamar berdinding keramik mempunyai suhu yang lebih rendah. Penelitian yang dilakukan olehAnisum dkk (2016) dengan mengukur suhu dan kelembaban udara dalam rumah jamur, menunjukkan bahwa banggunan dengan evaporate cooler menggunakan air mampu menurunkan suhu udara dan meningkatkan kelembaban udara dalam rumah jamur, sedangkan penelitian yang dilakukan oleh bimo dkk (2017) tentang pengukuran suhu dan kelembaban pada tanah dan udara diadapatka nilai suhu yang tidak sesuai dengan teori.

\section{KESIMPULAN}

Dari tiga eksperimen yang dilakukan dengan tiga kondisi yang berbeda nampak adanya perbedaan dalam suhu dan kelembaban. Dalam eksperimen terkait suhu nampak adanya perbedaan yang cukup signifikan bahwa kamar berdinding keramik mempunyai suhu yang lebih rendah. Tetapi hasil dari eksperimen kelembaban tidak bisa diambil kesimpulan khusus karena ada kondisi di kamar dengan suhu lebih rendah kadang memiliki kelembaban yang lebih rendah dan terkadang lebih tinggi.Sesuai dengan teori bahwa konduktifitas keramik memang tidak terlalu baik, sehingga kamar dengan berdinding keramik memiliki suhu yang lebih rendah karena panas dari luar kamar tidak bisa masuk ke kamar dengan baik. Selain itu terkait thermal comfort, kami juga melakukan wawancara terhadap 3 orang yang merasakan kedua kamar tersebut. Pertanyaan yang kami ajukan adalah lebih nyaman manakah antara kamar dengan dinding keramik dan tanpa dinding keramik. Dari ketiga narasumber diperoleh jawaban yang sama yaitu kamar dengan dinding keramik dirasa lebih nyaman atau sejuk.

\section{DAFTAR PUSTAKA}

Anisum, Bintoro. N, Goenadi. S, . 2016. Analisis Distribusi Suhu dan Kelembaban Udara dalam Rumah Jamur (Kumbung) menggunakan Computational Fluid Dynamics (CFD). Jurnal Agritech Vol 36 No 1.

ASHRAE. 2004. Thermal Environtments Condition for Human Occupancy (ASHRAE Standard 55). ASHRAE. Atlanta US.

Baharuddin. 2014. Analisis Perolehan Radiasi Matahari pada Berbagai Orientasi Bidang Verikal. Prosiding Temu Ilmiah IPLBI. 
Jurnal Inkofar * Volume 1 No. 2, Desember 2020 * ISSN: 2615-3645 (Print) / 2581-2920 (Online) Tersedia secara online di: http://www.politeknikmeta.ac.id/meta/ojs/

Bimo, A., Syifaurrahman, D., Ramadhan, M., Listiana, N., Analisis Pengukuran Suhu dan Kelembaban pada Tanah dan Udara. 2015. Prosiding Temu Ilmiah PLBI.

Nasrullah, Rahim. R, Baharuddin, Mulyadi. R, Jamala. N, Kusno. A. 2015. Temperatur dan Kelembaban Relatif Udara Outdoor. Prosiding Temu Ilmiah IPLBI.

ISO-7730. 1994. Moderate Thermal EnvironmentsDetermination of The PMV and PPD Indices and Specification of The Conditiions for Thermal Comfort. Switzerland. International Organization for Standardization.

Sangkertadi. 2013. Kenyamanan Termis di Ruang Luar Beriklim Tropis Lembab. Alfabeta. Bandung

Soegijono. 1999. Bangunan di Indonesia dengan Iklim Tropis Lembab Ditinjau dari Aspek Fisika Bangunan. Direktorat Jenderal Pendidikan Tinggi Departemen Pendidikan dan Kebudayaan. Jakarta. 